\title{
Vascular homeostasis in early (normo-albuminuric) type 2 diabetic nephropathy
}

\author{
Narisa Futrakul ${ }^{\mathrm{a}}$, Punnee Butthep ${ }^{\mathrm{b}}$, Sirichan Chunhakan ${ }^{\mathrm{b}}$, Wansa Banyatsuppasin ${ }^{\mathrm{b}}$, Prasit Futrakul ${ }^{\mathrm{a}}$ \\ ${ }^{a}$ Faculty of Medicine, Chulalongkorn University, Bangkok 10330; ${ }^{b}$ Faculty of Medicine, Ramathibodi \\ Hospital, Mahidol University, Bangkok 10440, Thailand.
}

\begin{abstract}
Background: Renal microvascular disease and reduction in peritubular capillary flow are generally observed in type 2 diabetic nephropathy (DN). Earlier therapeutic strategy with vasodilators has improved renal function in normo-albuminuric type $2 \mathrm{DN}$.

Objective: Study the mechanism of vascular homeostasis in twenty patients associated with normo-albuminuric type 2 DN.

Results: Angiogenic factors were observed in normo-albuminuric type $2 \mathrm{DN}$, where vascular endothelial growth factor (VEGF), was $420 \pm 341$ vs. 428 \pm 291 pg/mL (normal), and vascular endothelial growth factor - receptor 1 (VEGF-R1) was $60 \pm 12$ vs. $49 \pm 5 \mathrm{ng} / \mathrm{mL}$ (normal), which were not significantly different from the controls. Anti-angiogenic factors were observed in normo-albuminuric type $2 \mathrm{DN}$, where angiopoietin-2, was $2309 \pm 1125$ vs. $1671 \pm 835 \mathrm{pg} / \mathrm{mL}$ (normal), and vascular endothelial growth factor - receptor 2 (VEGF-R2) was 5715 $\pm 1400 \mathrm{vs.6126 \pm}$ $1060 \mathrm{ng} / \mathrm{mL}$ (normal), which were not significantly different from the controls.

Conclusion: The mechanism of vascular homeostasis was adequately functional in normo-albuminuric type $2 \mathrm{DN}$. This mechanism may explain the positive response to vasodilators and improved renal function in early stage of type 2 DN following the vasodilator treatment.
\end{abstract}

Keywords: Enhanced renal perfusion, normo-albuminuric type 2 diabetic nephropathy, vascular homeostasis, restoring renal function.

Type 2 diabetic nephropathy (DN) has been recognized as the primary cause of end-stage renal disease worldwide today $[1,2]$. Therapeutic strategy under present practice for type $2 \mathrm{DN}$ reflects by the presence of micro-albuminuria, or change in serum creatinine level. It simply slows the renal disease progression, but is unable to restore renal perfusion or function [3-5]. Since micro-albuminuria or elevated serum creatinine correlates with the decline in actual creatinine clearance at the 50 percent level of normal, the present therapeutic strategy in type $2 \mathrm{DN}$ usually initiated at the late stage of chronic kidney disease (CKD) cannot restore the renal perfusion or function. Recent studies explain such present therapeutic

Correspondence to: Professor Narisa Futrakul, Faculty of Medicine, Chulalongkorn University, Rama IV Rd, Bangkok 10330, Thailand.E-mail: fmednft@yahoo.com failures that are due to the impaired mechanism of vascular repair observed in late stage of DN [6, 7].

Recent therapeutic benefits are associated with enhanced renal perfusion as well as renal function with multidrug vasodilators that are documented in early stage of type $2 \mathrm{DN}$ and early stage of CKD [8-11]. It is of clinical importance to explain such therapeutic benefit. In this study, we investigated the mechanism of vascular homeostasis in early stage of type $2 \mathrm{DN}$ (normo-albuminuria).

\section{Material and methods}

This study was approved by the Research and Ethics Committee of the King Chulalongkorn Memorial Hospital.

A perspective cross -sectional study was performed in 20 patients associated with early stage of type $2 \mathrm{DN}$ that are characterized by the mean 
average of actual creatinine clearance of $87+22 \mathrm{~mL} /$ $\mathrm{min} / 1.73 \mathrm{~m}^{2}$ vs. normal $119 \pm 17 \mathrm{~mL} / \mathrm{min} / 1.73 \mathrm{~m}^{2}$ $(\mathrm{p}<0.05)$. The status of DN was defined by the abnormally elevated fractional excretion of magnesium (FE Mg) $4.6 \pm 1.5 \%$ vs. $1.9 \pm 0.2 \%$ (normal), where $\mathrm{p}<0.05$, because the abnormally elevated FE Mg reflected the presence of tubulointerstitial fibrosis [4]. The mean value of micro-albuminuria /creatinine ratio observed in these patients was $18 \pm 1.6 \mathrm{mg} / \mathrm{gram}$ creatinine (normal $<30 \mathrm{mg} /$ gm creatinine).

\section{Enzyme-linked immunosorbent assay (ELISA) for vascular endothelial growth factor (VEGF)}

The quantitative sandwich enzyme immunoassay technique was used for this assay. Standards and samples were pipetted into the wells, and any VEGF present was bound by the immobilized antibody. After washing away any unbound substances, an enzymelinked polyclonal antibody specific for VEGF was added to the wells. Following a wash to remove any unbound antibody enzyme regent, a substance solution was added to the wells, and color develops in proportion to the amount of VEGF bound in the initial step, the color development was stopped and the intensity of the color is measured.

\section{Human angiopoietin-2, VEGFR1, VEGFR2 immunoassays}

The quantitative sandwich enzyme immunoassay technique was used for these assays. This manner was similar with the above assay.

\section{Renal function study}

An endogenous creatinine clearance $(\mathrm{CCr}$ ) through a 10 hours urinary collection was performed, as previously described [4]. No diuretic was administered during within 24 hours before the test. Briefly, after a regular supper, no additional food except drinking water $a d$ lib was allowed. The patients were instructed to void at $7 \mathrm{PM}$, and urine was collected from $7 \mathrm{PM}$ to $5 \mathrm{AM}$. Clotted blood from venipuncture was drawn at the end of the test for the analysis of creatinine and magnesium levels. Urine samples were analyzed with the same blood samples obtained at the Renal Metabolic Laboratory Unit. For analysis of creatinine and magnesium, we used the methods described by Faulkner and King, and Atomic Absorption Spectrophotometer (model 1100G, Perkin Elmer, Norwalk, USA), respectively.
The value of CCr was converted to the body surface area of $1.73 \mathrm{~m}^{2}$ by the formula:

$$
\text { Body surface area }=\frac{\text { Body weight }(\mathrm{kg}) \mathrm{x} 4+7}{90+\text { body weight }(\mathrm{kg})}
$$

A reflection of tubular function or tubulointerstitial fibrosis was derived from FE Mg level that was calculated using the formula:

FE Mg = [(urine magnesium)/plasma magnesium $\mathrm{x}$ (plasma creatinine)/urine creatinine $\mathrm{x}$ 100]

\section{Statistical analysis}

Comparison of the sample mean of two quantitative variables was determined by the nonparametric method using the Mann-Whitney test. Pvalues below 0.05 were considered to be significant.

\section{Results}

Figure 1 shows angiogenic factors, namely vascular endothelial growth factor, vascular endothelial growth factor receptor 1 (VEGF, VEGFR1) measured in normo-albuminuric type $2 \mathrm{DN}$. Figure 2 shows antiangiogenic factors, namely angiopoietin-2, vascular endothelial growth factor receptor 2 (VEGFR2), measured in normo-albuminuric type 2 DN. No angiogenic factors and anti-angiogenic factors were not significantly different from normal as indicated in Fig. 1, and 2.

\section{Discussion}

It has been a unifying concept that renal microvascular disease is the crucial determinant of renal disease progression [12-15]. In this essence, the preferential constriction at the efferent arteriole, so-called hemodynamic maladjustment, contributes to sustained renal ischemia, and eventually tubulointerstitial fibrosis. A successful restoration of renal perfusion and renal function has been repeatedly demonstrated in terms of the hemodynamic maladjustment with adequate multidrug vasodilators, such as angiotensin converting enzyme inhibitor (ACEI), angiotensin II, receptor blocker, in patients at the early stage CKD and DN $[8,9,16,17]$. Such therapeutic approach enhances peritubular capillary flow, and restores actual creatinine clearance.

In the present study, we revealed an adequate mechanism of vascular repair in normo-albuminuric type $2 \mathrm{DN}$, which contrasts the impaired mechanism of vascular repair observed in late study of DN. In fact, an adequate amount of VEGF would activate 

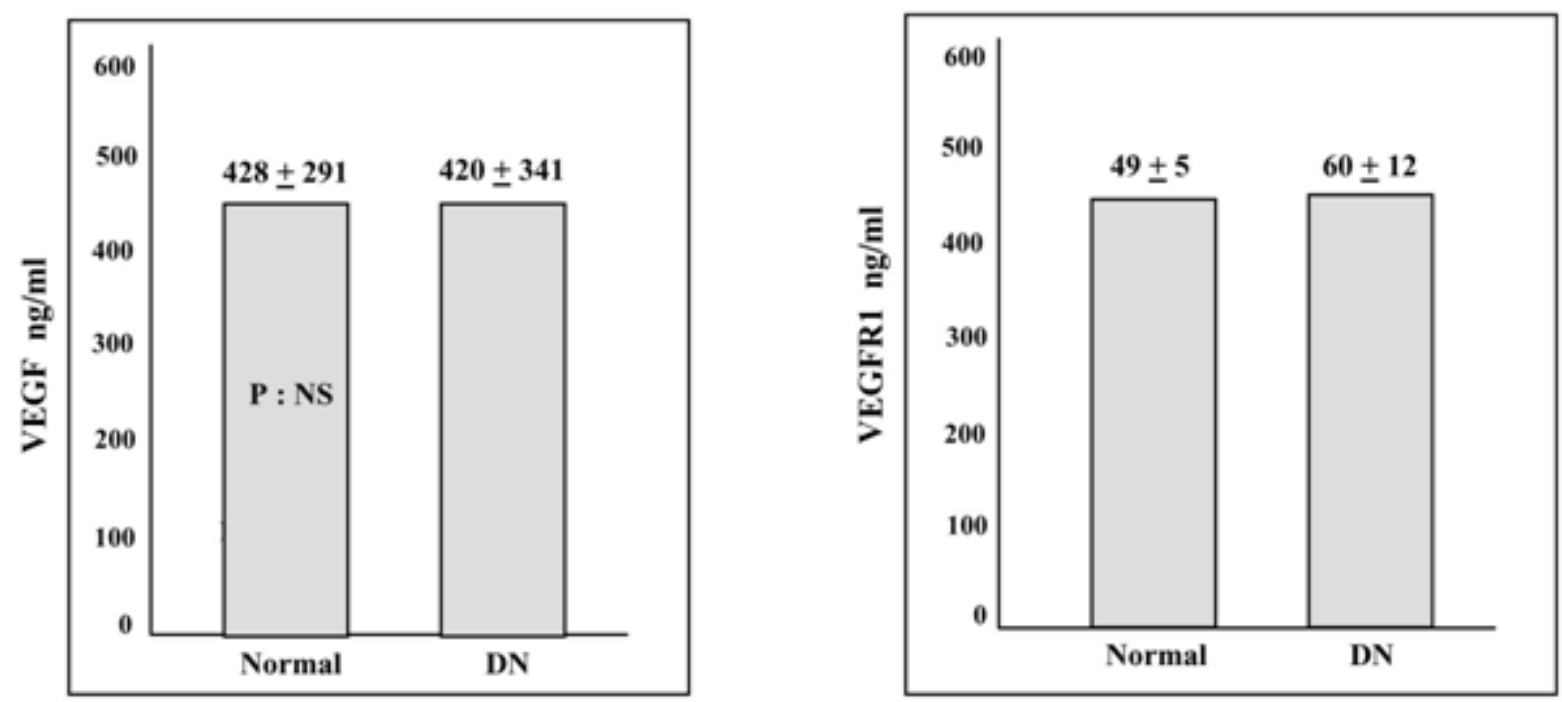

Fig. 1 Angiogenic factors measured in normo-albuminuric type 2 DN. P:NS=not significant.
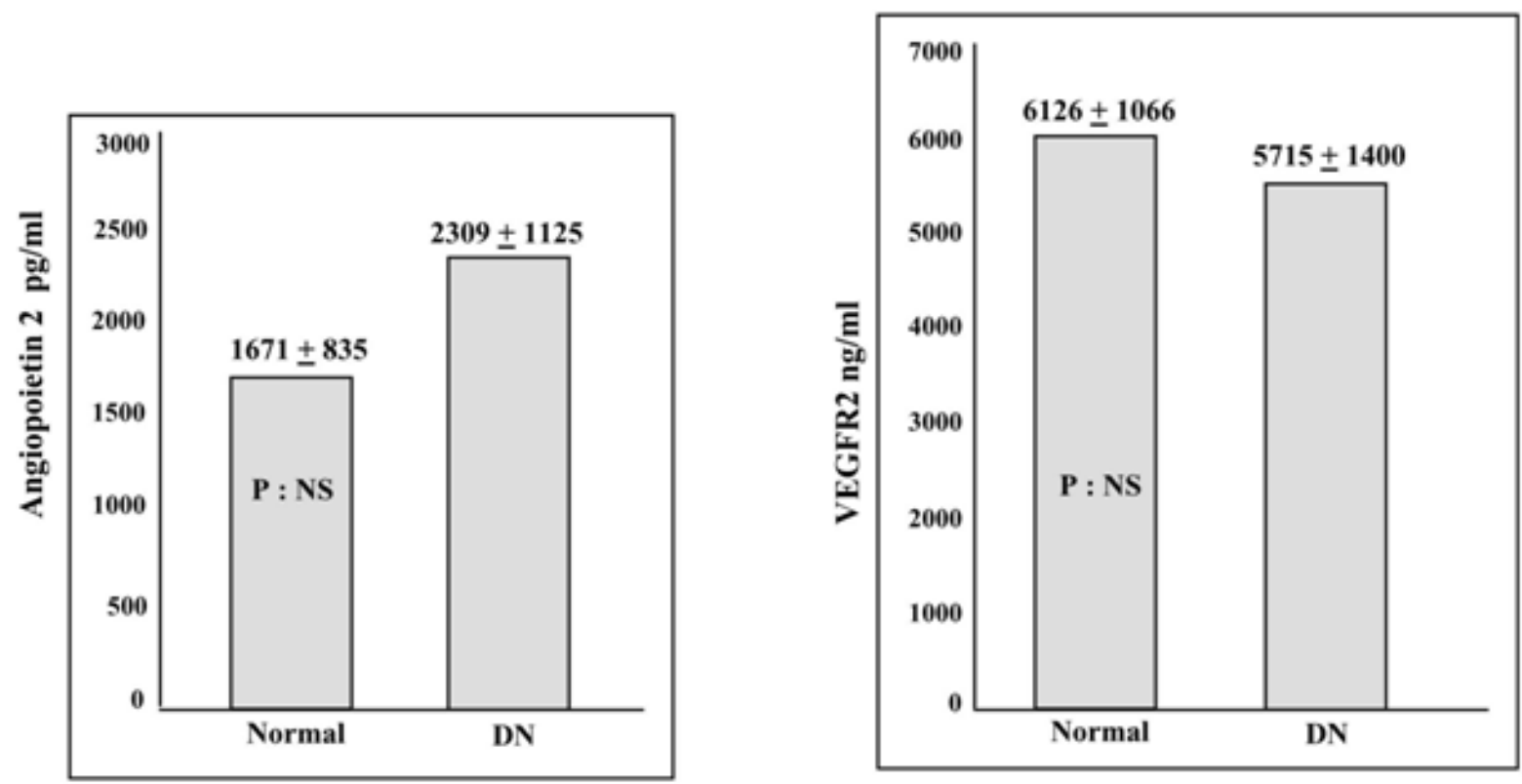

Fig. 2 Antiangiogenic factors measured in normo-albuminuric type 2 DN. P:NS=not significant.

through the normal level of vascular endothelial growth factor receptor 1(VEGFR1), by which it would induce Akt phosphorylation, coupling of endothelial nitric oxide synthase (eNOS), and eventually enhance NO (nitric oxide) production to induce vasodilation in response to vasodilators. In addition, an adequate amount of endothelial progenitor cells observed in the early stage of type $2 \mathrm{DN}$, in conjunction with the NO production, would synergistically induce proliferation of endothelial cells and replace the endothelial cells that were lost during the process of vascular injury [18]. Collectively, neoangiogenesis or vasculogenesis would be induced in renal vasculature. An adequate vascular repair would enhance renal perfusion, in particular, the peritubular capillary flow that directly supplies the tubulointerstitial structure. Improved 
vascular perfusion would induce renal regeneration to the tubulointerstitial structure, which is usually reflected by the reduction in the level of fractional excretion of magnesium, in conjunction with the increased level of creatinine clearance. This new conceptual view of focusing the therapeutic strategy at the early stage of type $2 \mathrm{DN}$ would effectively restore renal function, and eventually prevent the endstage renal disease. Present therapeutic failure is due to the unawareness of most type $2 \mathrm{DN}$ patients at the early stage under the environment favorable for vascular repair and renal regeneration.

In conclusion, implementation of vasodilators treatment at the early stage of DN can effectively prevent the disease progression towards end-stage renal disease.

\section{Acknowledgement}

We acknowledge the supports of National Research Council Fund of Thailand, Thailand Research Fund and the Science Division, Royal Institute of Thailand. The authors have no conflict of interest to report.

\section{References}

1. Babose TDJr. American Society of Nephrology presidential address 2006: chronic kidney disease as a public health threat: new strategy for a growing problem. J Am Soc Nephrol. 2008; 18:1038-45.

2. Parving HH, Lehnert H, Brochner -Mortensen J, Gomis $\mathrm{R}$, Anderson S, Arner P, et al. The effect of irbesartan on the development of diabetic nephropathy in patients with type 2 diabetes. N Engl J Med. 2001; 345:870-8.

3. Futrakul N, Vongthavarawat V, Sirisalipotch S, Chairatanarat T, Futrakul P, Suwanwalaikorn S. Tubular dysfunction and hemodynamic alteration in normoalbuminuric type 2 diabetes. Clin Hemorheol Microcirc. 2005; 32:59-65.

4. Futrakul P, Yenrudi S, Futrakul N, Sensirivatana R, Kingwatanakul P, Jungthirapanich J, et al. Tubular function and tubulointerstitial disease. Am J Kidney Dis. 1999; 33:886-91.

5. Futrakul N, Sila-asna M, Futrakul P. Therapeutic strategy towards renal restoration in chronic kidney disease. Asian Biomed. 2007; 1:33-44.

6. Futrakul N, Butthep P, Futrakul P. Altered vascular homeostasis in type 2 diabetic nephropathy (late). Ren Fail. 2009; 31:207-10.

7. Futrakul N, Butthep P, Futrakul P. Altered vascular homeostasis in chronic kidney disease. Clin
Hemorheol Microcirc. 2008; 38:201-7.

8. Futrakul N, Butthep P, Futrakul P, Sitprija V. Improvement of renal function in type 2 diabetic nephropathy. Ren Fail. 2007; 29:155-8.

9. Ritt M, Ott C, Raff U, Schneider MP, Schuster I, Hilgers $\mathrm{KF}$, et al. Renal vascular endothelial function in hypertensive patients with type 2 diabetis mellitus. Am J Kidney Dis. 2009; 53:281-9.

10. Futrakul N, Futrakul P. Improved vascular repair is relevant to enhanced renal function with vasodilators in early stage of chronic kidney disease. Asian Biomed. 2010; 4:153-7.

11. Futrakul N, Futrakul P. Vascular repair is vulnerable to renal regeneration in early stage of diabetic nephropathy (letter to editor). Asian Biomed. 2010; 4: 827-8.

12. Bohle AC, Mackensen-Haen S, Wehrmann M. Significance of postglomerular capillaries in the pathogenesis of chronic renal failure. Kidney Blood Press Res. 1996; 19:191-5.

13. Kang DH, Kanellis J, Hugo C, Truong L, Anderson S, Kerjaschki D, et al. Role of the microvascular endothelium in progressive renal disease. J Am Soc Nephrol. 2002; 13:806-816.

14. Nakagawa T, Kang DH, Ohashi R, Suga S, HerreraAcosta J, Rodriguez-Iturbe B, et al. Tubulointerstitial disease: role of ischemia and microvascular disease. Cur Opin Nephrol Hyperten. 2003; 12:233-41.

15. Futrakul N, Yenrudi S, Sensirivatana R, Watana D, Laohapaibul A, Watanapenphaibul K, et al. Peritubular capillary flow determines tubulointerstitial disease in idiopathic nephrotic syndrome. Ren Fail. 2000; 22: 329-35.

16. Futrakul N, Butthep P, Vongthavarawat V, Futrakul P, Sirisalipoch S, Chairatanalat T, et al. Early detection of endothelial injury and dysfunction in conjunction with correction of hemodynamic maladjustment can effectively restore renal function in type 2 diabetic nephropathy. Clin Hemorheol Microcirc. 2006; 34: 373-382.

17. Futrakul N, Futrakul P, Siriviriyakul P. Corection of peritubular capillary flow reduction with vasodilators restores function in focal segmental glomerulosclerotic nephrosis. Clin Hemorheol Microcirc. 2000; 31:197-205.

18. Kawasaki K, Smith RS, Hsinh C-M, Sun J, Chao J, Liao JK. Activation of the phosphatidylinositol 3-kinase/ protein kinase Akt pathway modiates nitric oideinduced endothelial cell migration and angiogenesis. Mol Cell Biol. 2003; 23:5726-37. 